\title{
Rhamnolipid Biosurfactant Complexation of Rare Earth Elements
}

\author{
David E. Hogan ${ }^{a}$, Joan E. Curry ${ }^{a}$, Jeanne E. Pemberton ${ }^{b}$, and Raina M. Maier ${ }^{*}$
}

a Department of Soil, Water and Environmental Science, University of Arizona, P.O.

Box 210038, Tucson, AZ 85721, USA

${ }^{b}$ Department of Chemistry and Biochemistry, University of Arizona, P.O. Box 210041, Tucson, AZ 85721, USA

\section{ABSTRACT}

Rare earth elements (REE) are vital for modern technologies and considered critical materials. This study investigated monorhamnolipid biosurfactant interactions with REE as the basis for REE recovery technology. Conditional stability constants $(\log \beta)$, measured using a resin-based ion exchange method, are reported for 16 REE and metals. These results were combined with existing data for 10 other metals to assess comparative strength and determinants of binding. The stability constants could be divided into three groups: weakly, moderately, and strongly bound. The REE were all in the strongly bound group $\left(\mathrm{UO}_{2}^{2+}, \mathrm{Eu}^{3+}, \mathrm{Nd}^{3+}, \mathrm{Tb}^{3+}, \mathrm{Dy}^{3+}, \mathrm{La}^{3+}, \mathrm{Cu}^{2+}, \mathrm{Al}^{3+}, \mathrm{Pb}^{2+}, \mathrm{Y}^{3+}, \mathrm{Pr}^{3+}\right.$, and $\left.\mathrm{Lu}^{3+}\right)$ with $\log \beta$ ranging from 9.82 to 8.20 . The elements $\mathrm{Cd}^{2+}, \mathrm{In}^{3+}, \mathrm{Zn}^{2+}, \mathrm{Fe}^{3+}, \mathrm{Hg}^{2+}$, and $\mathrm{Ca}^{2+}$ were moderately bound with $\log \beta=7 \cdot 17-4.10$. Finally, $\mathrm{Sr}^{2+}, \mathrm{Co}^{2+}, \mathrm{Ni}^{2+}, \mathrm{UO}_{2}{ }^{2+}, \mathrm{Ba}^{2+}$, $\mathrm{Mn}^{2+}, \mathrm{Mg}^{2+}, \mathrm{Rb}^{+}$, and $\mathrm{K}^{+}$were weakly bound with $\log \beta=3.95-0.96$. Two $\log \beta$ values are reported for the uranyl ion due to two distinct binding regions. A mixed metals study and associated selectivity coefficients confirmed monorhamnolipids preferentially remove metals with large $\log \beta$ values over those with smaller values. 
Preferential complexation by monorhamnolipids may constitute a green pathway for recovery of REE from alternative, non-traditional sources.

\section{KEYWORDS}

Rhamnolipid, metal complexation, rare earth element, biosurfactant, stability constants

\section{INTRODUCTION}

An Intel computer chip requires nearly 60 periodic elements to produce [1], and a widely recognized future challenge will be maintaining a steady supply of these elements [2]. This is especially true for rare earth elements (REE) which are essential components of every modern technology including green energy, personal electronics, data transmission, medical technologies, reaction catalysts, aircraft, and optics [3]. The U.S. Department of Energy lists the rare earth metals dysprosium, neodymium, terbium, europium, and yttrium as critical materials subject to supply risk [4]; the European Union has identified a longer list of materials which includes indium and additional REE [5]. Demand for REE was estimated at 136,100 tons in 2010 and is expected to continue to increase [6]. Due to the limited number of economically viable ore bodies for mining these materials, it is critical alternative technologies be developed to utilize all possible REE resources.

One untapped source for REE is industrial waste streams. Despite considerable REE concentrations in aqueous waste streams from hard rock mining $[7,8]$ and coal mining $[9,10]$, REE are not currently targeted for recovery from 
these sources. Additional potential sources include other industrial waste streams [11], municipal wastewaters [12], and landfill leachates [13].

One approach to recover metals from waste streams is the use of metal complexing agents. These compounds should be selective for target metals, even when at low concentration, because most waste streams contain competing metals $\left(\mathrm{K}^{+}, \mathrm{Ca}^{2+}\right.$, etc. $)$ at orders-of-magnitude higher concentrations. A second consideration is that the use of complexing agents to capture metals from waste streams will ultimately lead to the release of some of this material to the environment even under controlled conditions. Thus, agents that are non-toxic, naturally-derived, and renewable would be ideal for minimizing the potential for environmental contamination during the metal recovery process. Biosurfactants are green molecules with properties that may suit this challenge well.

Biosurfactants are compounds that exhibit surface activity (e.g., reduce surface and interfacial tension) and are derived from natural, biological sources. They are considered green substances due to their natural derivation, biodegradability, and relatively low toxicity [14]. Rhamnolipids produced by Pseudomonas aeruginosa are a class of biosurfactants known to complex metals. They are produced as a complex congener mixture where the molecule may have a mono-rhamnose or di-rhamnose hydrophilic moiety linked by an O-glycosidic bond to a hydrophobic moiety of one, two, or three (rarely) hydrocarbon chains which are primarily saturated, although mono-and polyunsaturated congeners exist [14]. 
Monorhamnolipids (rhamnosyl- $\beta$-hydroxyalkanoyl- $\beta$-hydroxyalkanoates), (Fig. 1A insert) are the best-studied rhamnolipids for metal complexation behavior. Cadmium was the first metal reported to be complexed by monorhamnolipids [15], and subsequent studies expanded the list of transition metals [16, 17]. Monorhamnolipid-metal complexes are typically reported in terms of their conditional stability constants, a measure of the affinity of a complexing agent for a metal cation under specific solution conditions [18]. These studies showed monorhamnolipids have conditional stability constants for heavy metal cations $\left(\mathrm{Pb}^{2+}, \mathrm{Cd}^{2+}, \mathrm{Zn}^{2+}\right)$ that are several orders of magnitude larger than for common soil/water cations [17].

To date, rhamnolipid interactions with REE have not yet been examined, but given the strong complexing ability of these biosurfactants with transition metals, it was hypothesized that they would also complex REE. This hypothesis was tested by: (1) determining the ability of monorhamnolipids to complex REE and other metals identified as critical with a supply risk, and (2) assessing the ability of monorhamnolipids to selectively remove metals from mixed metal solutions. Monorhamnolipids from Pseudomonas aeruginosa ATCC 9027 were used for all experiments. An ion exchange technique was used to determine the conditional stability constants for monorhamnolipids with $\mathrm{Y}^{3+}, \mathrm{La}^{3+}, \mathrm{Pr}^{3+}, \mathrm{Nd}^{3+}, \mathrm{Eu}^{3+}, \mathrm{Tb}^{3+}, \mathrm{Dy}^{3+}$, $\mathrm{In}^{3+}, \mathrm{Lu}^{3+}, \mathrm{Al}^{3+}, \mathrm{UO}_{2}{ }^{2+}, \mathrm{Sr}^{2+}, \mathrm{Ba}^{2+}, \mathrm{Cd}^{2+}, \mathrm{Pb}^{2+}$, and $\mathrm{Rb}^{+}$. In addition, the ability of monorhamnolipids to selectively remove metals in the presence of competing metals at equimolar and order-of-magnitude higher concentrations was tested using ion exchange with the metals $\mathrm{Ca}^{2+}, \mathrm{Cd}^{2+}, \mathrm{Pb}^{2+}$. 


\section{MATERIALS AND METHODS}

\subsection{Monorhamnolipid Production}

Pseudomonas aeruginosa ATCC 9027 was obtained from the American Type Culture Collection and kept as a glycerol freezer stock at $-80^{\circ} \mathrm{C}$. This strain is a natural mutant that has been previously shown to exclusively produce monorhamnolipid congeners [19]. Monorhamnolipid was produced as follows: $P$. aeruginosa was cultured for $24 \mathrm{~h}$ at $37^{\circ} \mathrm{C}$ on PTYG agar ( $0.5 \%$ protease peptone, $0.5 \%$ tryptone, $1 \%$ yeast extract, $0.06 \% \mathrm{MgSO}_{4} \cdot 7 \mathrm{H}_{2} \mathrm{O}, 7 \times 10^{-4} \% \mathrm{CaCl}_{2} \cdot 2 \mathrm{H}_{2} \mathrm{O}$, and $1 \%$ glucose). The agar culture was transferred to Kay's mineral medium for $24 \mathrm{~h}$ growth at $37^{\circ} \mathrm{C}$ and $200 \mathrm{rpm}$. Kay's mineral medium contains $100 \mathrm{~mL}$ of solution $\mathrm{A}$ $\left(0.3 \% \mathrm{NH}_{4} \mathrm{H}_{2} \mathrm{PO}_{4}, 0.2 \% \mathrm{~K}_{2} \mathrm{HPO}_{4}\right.$, and $0.2 \%$ glucose $), 1 \mathrm{~mL}$ solution $\mathrm{B}(0.025 \%$ $\left.\mathrm{FeSO}_{4} \cdot 7 \mathrm{H}_{2} \mathrm{O}\right)$ and $1 \mathrm{~mL}$ solution $\mathrm{C}\left(10 \% \mathrm{MgSO}_{4} \cdot 7 \mathrm{H}_{2} \mathrm{O}\right)$. The pre-culture was transferred to a pH 7 minimal salts medium (MSM) with $2 \%$ glucose at a ratio of 1 $\mathrm{mL}$ pre-culture per $100 \mathrm{~mL}$ MSM. MSM is composed of $1 \mathrm{~L}$ of solution $\mathrm{A}(0.25 \%$ $\mathrm{NaNO}_{3}, 0.04 \% \mathrm{MgSO}_{4} \cdot 7 \mathrm{H}_{2} \mathrm{O}, 0.1 \% \mathrm{KCl}, 0.1 \% \mathrm{NaCl}, 0.005 \% \mathrm{CaCl}_{2} \cdot 2 \mathrm{H}_{2} \mathrm{O}$, and $\left.0.4 \% \mathrm{H}_{3} \mathrm{PO}_{4}\right)$ mixed with $1 \mathrm{~mL}$ of solution $\mathrm{B}\left(0.05 \% \mathrm{FeSO}_{4} \cdot 7 \mathrm{H}_{2} \mathrm{O}, 0.15 \%\right.$ $\mathrm{ZnSO}_{4} \cdot 7 \mathrm{H}_{2} \mathrm{O}, 0.15 \% \mathrm{MnSO}_{4} \cdot \mathrm{H}_{2} \mathrm{O}, 0.03 \% \mathrm{H}_{3} \mathrm{BO}_{3}, 0.015 \% \mathrm{CoCl}_{2} \cdot 6 \mathrm{H}_{2} \mathrm{O}, 0.015 \%$ CuSO ${ }_{4} \cdot 5 \mathrm{H}_{2} \mathrm{O}$, and $0.01 \% \mathrm{Na}_{2} \mathrm{MoO}_{4} \cdot 2 \mathrm{H}_{2} \mathrm{O}$ ). The $\mathrm{MSM}$ culture was placed in a $37^{\circ} \mathrm{C}$ gyratory shaker and shaken for $72 \mathrm{~h}$ at $200 \mathrm{rpm}$.

\subsection{Monorhamnolipid Purification}

Monorhamnolipids produced by Pseudomonas aeruginosa ATCC 9027 are a congener mixture of up to 30 molecules in which the rhamnose headgroup is preserved but the alkyl chains can vary in chain length and, to a lesser extent, 
saturation [20]. The protocol used for this work generates a pure mixture in which the major congener, rhamnosyl- $\beta$-hydroxydecanoyl- $\beta$-hydroxydecanoate (RhaC10-C10), typically dominates at $75-85$ wt\% of the mixture $[20,21]$. This complex assembly of congeners is referred to herein as either the monorhamnolipid mixture or simply monorhamnolipids.

The monorhamnolipid mixture was concentrated by centrifugation $(17,696 \mathrm{~g}$ for $10 \mathrm{~min}$ ) to remove cellular debris from the MSM culture, followed by removal and acidification of the supernatant to $\mathrm{pH} 2$ using $\mathrm{HCl}$. Monorhamnolipids have $\mathrm{pK}_{\mathrm{a}}$ values of $\sim 5$, below which they become poorly soluble [19] and can be collected by centrifugation. Pelleted monorhamnolipids were dissolved in a 9:1 chloroform:methanol mixture and separated from remnant water using a separatory funnel. The solvent was removed by rotoevaporation. The concentrated monorhamnolipids were purified using a solvent mixture of $6: 6: 6: 1: 1(\mathrm{v} / \mathrm{v})$ of hexane:dichloromethane:ethyl acetate:chloroform:methanol (containing $0.1 \%$ acetic acid) by elution through a $22 \times 300 \mathrm{~mm}$ gravity-based, glass chromatography column packed with $45 \mathrm{~g}$ of 60 -Å-pore silica gel. Monorhamnolipids were collected when column eluent tested positive for rhamnose with anthrone reagent dissolved in $\mathrm{H}_{2} \mathrm{SO}_{4}$. The solvent mixture was removed from the monorhamnolipids by rotoevaporation, and purity was checked by reverse phase high performance liquid chromatography on a C18 column [19].

\subsection{Metals}

$$
\mathrm{Pb}\left(\mathrm{NO}_{3}\right)_{2}, \mathrm{Cd}\left(\mathrm{NO}_{3}\right)_{2} \bullet 4 \mathrm{H}_{2} \mathrm{O}, \mathrm{Y}\left(\mathrm{NO}_{3}\right)_{3} \bullet 4 \mathrm{H}_{2} \mathrm{O}, \mathrm{Ba}\left(\mathrm{NO}_{3}\right)_{2}, \mathrm{Sr}\left(\mathrm{NO}_{3}\right)_{2} \text {, }
$$

$\ln \left(\mathrm{NO}_{3}\right)_{3} \cdot \times \mathrm{H}_{2} \mathrm{O}, \mathrm{Lu}\left(\mathrm{NO}_{3}\right)_{3} \cdot \mathrm{xH}_{2} \mathrm{O}, \mathrm{La}\left(\mathrm{NO}_{3}\right)_{3} \cdot 6 \mathrm{H}_{2} \mathrm{O}, \mathrm{UO}_{2}\left(\mathrm{NO}_{3}\right)_{2} \cdot 6 \mathrm{H}_{2} \mathrm{O}, \mathrm{Rb}\left(\mathrm{NO}_{3}\right)$, 
$\mathrm{Eu}\left(\mathrm{NO}_{3}\right)_{3} \cdot 5 \mathrm{H}_{2} \mathrm{O}, \mathrm{Tb}\left(\mathrm{NO}_{3}\right)_{3} \cdot 5 \mathrm{H}_{2} \mathrm{O}, \operatorname{Pr}\left(\mathrm{NO}_{3}\right)_{3} \cdot 6 \mathrm{H}_{2} \mathrm{O}, \mathrm{Nd}\left(\mathrm{NO}_{3}\right)_{3} \cdot 6 \mathrm{H}_{2} \mathrm{O}, \mathrm{Dy}\left(\mathrm{NO}_{3}\right)_{3} \cdot x \mathrm{H}_{2} \mathrm{O}$, and $\mathrm{Al}\left(\mathrm{NO}_{3}\right)_{3} \cdot 9 \mathrm{H}_{2} \mathrm{O}$ were purchased from Sigma-Aldrich with a purity of $\geq 99 \%$ and were used as received. The molecular weight of metal nitrates with an unknown degree of hydration $\left[\mathrm{M}^{\mathrm{n}+}\left(\mathrm{NO}_{3}\right)_{n} \cdot x \mathrm{H}_{2} \mathrm{O}\right]$ was determined experimentally. The metal concentration of a solution with known volume and salt mass was measured by inductively coupled plasma atomic emission spectroscopy (ICP-AES), and the mass of water added with the salt determined. ICP/AA grade standard solutions for each metal were obtained from Fisher Scientific.

\subsection{Determination of Conditional Stability Constants}

Monorhamnolipid-metal conditional stability constants were determined for each metal twice in triplicate $(n=6)$ using an ion-exchange technique $[16,17]$. The ion exchange resin SP Sephadex C25 (GE Healthcare) was prepared by soaking in ultrapure water $(\geq 18 \mathrm{M} \Omega-\mathrm{cm})$ overnight. The hydrated resin was washed with equal parts ultrapure water, then $\mathrm{pH} 6.9$ disodium PIPES buffer [Piperazine-N,N'bis(2-ethanesulfonic acid)], and air-dried; sufficient buffer was used to saturate the resin with $\mathrm{Na}^{+}$. lon exchange reactions occurred in $15-\mathrm{mL}$ polypropylene metal-free centrifuge tubes (VWR). Each reaction contained $100 \mathrm{mg}$ of prepared resin and a total volume of $10 \mathrm{~mL}$ with final concentrations of $0.5 \mathrm{mM}$ metal, $0.01 \mathrm{M}$ PIPES buffer at $\mathrm{pH} 6.9$, and $0,[0.1$ or 0.25$], 0.5,1,2$, or $4 \mathrm{mM}$ of the monorhamnolipid mixture. Uranyl was examined with the additional monorhamnolipid concentrations of 0.75 and $1.5 \mathrm{mM}$. In the absence of monorhamnolipids, $99 \%$ of the metal is bound for polyvalent ions and about $50 \%$ for monovalent ions. A $10 \mathrm{mM}$ monorhamnolipid (M.W. $504 \mathrm{~g} \mathrm{~mol}^{-1}$ ) stock solution was generated; 
monorhamnolipids were measured gravimetrically, dissolved in ultrapure water, and the solution adjusted to $\mathrm{pH}$ 6.9. Metal solutions were made with ultrapure water $0.5 \mathrm{~h}$ before use. Reactions were shaken horizontally on a gyratory shaker (200 rpm) for $2 \mathrm{~h}$ at room temperature, allowed to settle vertically for a minimum of $1 \mathrm{~h}$, and then a sample of supernatant was removed and diluted in trace metals grade $2 \% \mathrm{HNO}_{3}$. Metal concentrations were determined by ICP-AES. Calibration curves were prepared using standard solutions in trace metals grade $2 \% \mathrm{HNO}_{3}$.

\subsection{Conditional Stability Constant Calculation}

The monorhamnolipid-metal conditional stability constant was calculated as described previously $[16,17]$. The formation constant, or stability constant, $\beta$, is calculated by $\beta=\left[M L_{\chi}\right] /\left([M][L]^{\chi}\right)$ where $M$ is the metal $\left(\mathrm{mol} \mathrm{L}^{-1}\right), L$ is the monorhamnolipid ligand $\left(\mathrm{mol} \mathrm{L}^{-1}\right), M L_{X}$ is the metal:ligand complex $\left(\mathrm{mol} \mathrm{L}^{-1}\right)$, and $\mathrm{X}$ is the stoichiometry of the monorhamnolipid:metal complex $\left(\mathrm{mol} \mathrm{mol}^{-1}\right)$. The conditional stability constant has previously been reported as $\mathrm{K}$, but because multiple binding events have been shown to occur in this system, $\beta$ is a more appropriate designation for the overall stability constants reported herein; $\mathrm{K}$ is

related to $\beta$ by $\beta=K_{1} \cdot K_{2} \cdots K_{n}$ where each $\mathrm{K}_{\mathrm{n}}$ is a stability constant for stepwise addition of 1 to $x$ ligands [22]. The overall stability constant is determined using the linear relationship in Eq. 1.

$$
\log \left(\lambda_{o} / \lambda-1\right)=\log \beta+\chi \log L
$$

A linear regression of data plotted with $\log L$ vs. $\log \left(\lambda_{o} / \lambda-1\right)$ yields a y-intercept representing the stability constant, $\log \beta$, and a slope representing the ligand to 
metal stoichiometry, $\mathrm{X} \cdot \lambda_{o}$ and $\lambda$ are distribution coefficients where $\lambda_{o}=[M R] /[M]$ and $\lambda=[M R] /\left[\left(M+M L_{\chi}\right)\right] . M R$ is the metal bound to resin $\left(\mathrm{mol} \mathrm{kg}^{-1}\right)$. These constants are determined experimentally by measuring the metal concentration in solution after the ion exchange reactions have reached equilibrium. Stability constants determined using this method are only valid for the conditions of the experiment; thus, they are considered conditional stability constants and are only intended to demonstrate the relative binding strengths of monorhamnolipid across the metals tested. Data for these experiments represent the mean and standard deviation of 6 replicates.

\subsection{Metal Competition Study}

The preference of monorhamnolipid for different metals was examined in two mixed metal studies. $\mathrm{Ca}^{2+}, \mathrm{Cd}^{2+}$, and $\mathrm{Pb}^{2+}$ were selected as model elements for their small, intermediate, and large stability constants, respectively. The first study examined $\mathrm{Ca}^{2+}, \mathrm{Cd}^{2+}$, and $\mathrm{Pb}^{2+}$ at equimolar concentrations, and the second, at a ratio of 100:10:1, respectively. Reactions for the first study followed the procedure outlined in the previous section except each metal was present at a concentration of $0.167 \mathrm{mM}(0.5 \mathrm{mM}$ total). The same method was used for the second study as well, except only 0,1 , or $2 \mathrm{mM}$ monorhamnolipid was examined with metal concentrations of $0.45 \mathrm{mM} \mathrm{Ca}^{2+}, 0.045 \mathrm{mM} \mathrm{Cd}^{2+}$, and $0.0045 \mathrm{mM} \mathrm{Pb}^{2+}$ ( $0.5 \mathrm{mM}$ total metal). Metal concentrations were measured by ICP-AES. Calibration curves were prepared using standard solutions in trace-metals grade $2 \% \mathrm{HNO}_{3}$. In 
the former study, one set of triplicate measurements was performed $(n=3)$ and in the latter study two sets of triplicate measurements were performed $(n=6)$.

\subsection{Determination of Selectivity Coefficients}

Selectivity coefficients describe the partitioning of a ligand between two metals. The equilibrium equation that illustrates this partitioning is: $N L+M \rightleftarrows M L+$ $N$ where $M$ is the metal of interest and $N$ is any competing cation [23]. This equation is suitable for reactions where both metals bind with an equivalent number of ligands. When two metals bind to different number of ligands, the equilibrium equation to describe the partitioning is: $N L_{\chi_{N}}+M \rightleftarrows M L_{\chi_{M}}+N+$ $L\left(\chi_{N}-\chi_{M}\right)$. The selectivity of a ligand for $M$ over $N$ can then be described using the selectivity coefficient, $K_{N}^{M}$, defined by Eq. 2 :

$$
K_{N}^{M}=L\left(\chi_{N}-\chi_{M}\right)\left(\frac{\left[M L_{\chi_{M}}\right]}{[M]} \frac{[N]}{\left[N L_{\chi_{N}}\right]}\right)=L\left(\chi_{N}-\chi_{M}\right)\left(\frac{\left[M L_{\chi_{M}}\right]}{[M]} \div \frac{\left[N L_{\chi_{N}}\right]}{[N]}\right)
$$

Due to the method of sample collection, the solution concentrations of bound $\left(\left[M L_{\chi_{M}}\right]\right)$ and unbound metal $([M])$ could not be directly determined. Simplification of $\left(\lambda_{o} / \lambda-1\right)$ (described above) for $\mathrm{M}$ gives $\left(\left[M L_{\chi_{M}}\right]\right) /([M])$. Using this relationship, the selectivity coefficient was redefined and calculated using Eq. 3:

$$
K_{N}^{M}=L\left(\chi_{N}-\chi_{M}\right) \frac{\left(\lambda_{o M} / \lambda_{M}-1\right)}{\left(\lambda_{o N} / \lambda_{N}-1\right)}
$$

Selectivity coefficients were determined at $0.5,1$, and $2 \mathrm{mM}$ monorhamnolipid concentrations for the $\mathrm{Pb} / \mathrm{Cd}, \mathrm{Cd} / \mathrm{Ca}$, and $\mathrm{Pb} / \mathrm{Ca}$ metal pairs in the equimolar mixed metal study. Values for 0.25 and $4 \mathrm{mM}$ are not reported because metal in solution approaches either $0 \%$ (Ca for $0.25 \mathrm{mM}$ ) or $100 \%(\mathrm{~Pb}$ for $4 \mathrm{mM})$ where 
small changes have a large effect on the selectivity coefficient calculation. Chi values for each metal were determined in the equimolar study as described above.

Selectivity coefficients could not be determined for the order of magnitude mixed metal study because analytical error for $\mathrm{Pb}$ was relatively large at the low concentration utilized.

\section{RESULTS AND DISCUSSION}

\subsection{Single Metal Studies}

Thirteen previously unstudied metals (including select REE) and three previously studied metals $\left(\mathrm{Al}^{3+}, \mathrm{Pb}^{2+}\right.$, and $\left.\mathrm{Cd}^{2+}\right)$ were reacted with monorhamnolipids to determine the conditional stability constant and stoichiometry of monorhamnolipid:metal complexes (Table 1). As expected, metal complexation increases with increasing monorhamnolipid concentrations. Figure $1 \mathrm{~A}$ compares the increase in aqueous metal concentration of $\mathrm{Pb}^{2+}$ and $\mathrm{Sr}^{2+}$ with increasing monorhamnolipid concentration. $\mathrm{Pb}^{2+}$ is more effectively complexed, with $97 \%$ of the $\mathrm{Pb}^{2+}$ in the aqueous phase at $4 \mathrm{mM}$ monorhamnolipid, compared to $6.7 \%$ of $\mathrm{Sr}^{2+}$.

Complexation data were used to calculate conditional stability constants (log $\beta)$, a measure of complexation strength, and monorhamnolipid:metal complex stoichiometry (molar ratio ' $\mathrm{X}$ ') using Eq. 1. Figure 1B shows plots of $\log \left(\lambda_{o} / \lambda-1\right)$ as a function of $\log L$ for $\mathrm{Pb}^{2+}$ and $\mathrm{Sr}^{2+}$. Linear regression of these plots was performed to determine values for $\log \beta$ and $x$. Lead, the more strongly complexed metal (Fig. 1A) exhibits a larger slope and $y$-intercept indicating larger $\log \beta$ and $x$ 
values than $\mathrm{Sr}^{2+}$. Conversely, as the less strongly complexed metal, $\mathrm{Sr}^{2+}$ exhibits a smaller slope and y-intercept.

The metals $\mathrm{Al}^{3+}, \mathrm{Pb}^{2+}$, and $\mathrm{Cd}^{2+}$ were tested as a direct comparison to values reported previously by Ochoa-Loza et al. [17]. $\log \beta$ values for $\mathrm{Al}^{3+}, \mathrm{Pb}^{2+}$, and $\mathrm{Cd}^{2+}$ obtained in this study are within the $95 \%$ confidence intervals reported by Ochoa-Loza et al. demonstrating good agreement between the studies (Table 1).

$\log \beta$ values for the 16 metals examined in this study combined with data for 10 metals from Ochoa-Loza et al. [17] range from 9.82 to 0.96 (Table 1). The 26 metals were divided into three groups based on arbitrary $\log \beta$ values of $>8$ (strongly bound), $<8$ and $>4$ (moderately bound) and $<4$ (weakly bound). Strongly bound metals include $\mathrm{UO}_{2}^{2+}, \mathrm{Eu}^{3+}, \mathrm{Nd}^{3+}, \mathrm{Tb}^{3+}, \mathrm{Dy}^{3+}, \mathrm{La}^{3+}, \mathrm{Cu}^{2+}, \mathrm{Al}^{3+}, \mathrm{Pb}^{2+}, \mathrm{Y}^{3+}$, $\mathrm{Pr}^{3+}$, and $\mathrm{Lu}^{3+}$ with conditional stability constants ranging from 9.82 to 8.20 . Moderately bound metals include $\mathrm{Cd}^{2+}, \mathrm{In}^{3+}, \mathrm{Zn}^{2+}, \mathrm{Fe}^{3+}, \mathrm{Hg}^{2+}$, and $\mathrm{Ca}^{2+}$ with stability constants ranging from 7.17 to 4.10 . Weakly bound metals include $\mathrm{Sr}^{2+}$, $\mathrm{Co}^{2+}, \mathrm{Ni}^{2+}, \mathrm{UO}_{2}{ }^{2+}, \mathrm{Ba}^{2+}, \mathrm{Mn}^{2+}, \mathrm{Mg}^{2+}, \mathrm{Rb}^{+}$, and $\mathrm{K}^{+}$with stability constants ranging from 3.95 to 0.96 . The uranyl ion has two reported $\log \beta$ values due to the ion demonstrating two distinct binding regions (discussed below). These groupings reveal several trends. First, monorhamnolipids exhibit selectivity for REE which are all in the strongly bound stability constant group. Second, metals of environmental concern (e.g., $\mathrm{Cu}^{2+}, \mathrm{Pb}^{2+}, \mathrm{Cd}^{2+}, \mathrm{Zn}^{2+}, \mathrm{Hg}^{2+}$, and $\mathrm{Ni}^{2+}$ ) are in the strongly or moderately bound groups except for $\mathrm{Ni}^{2+}$. Third, common soil and water cations have smaller $\log \beta$ values that range from $0.96\left(\mathrm{~K}^{+}\right)$to $2.66\left(\mathrm{Mg}^{2+}\right)$ to $4.10\left(\mathrm{Ca}^{2+}\right)$. 
The coefficients of variation (CV) for $\log \beta$ values [(standard error/log $\beta$ ) $100 \%$ ] range from 2.1 to $18.6 \%$ (Table 1 ). The molar ratio values, $X$, range from 2.93 to 0.57 (Table 1). Non-integer values for $X$ are counterintuitive, as it is impossible to have 2.93 monorhamnolipid molecules, but there are several possibilities for why non-integer values are calculated. First, the values could be the result of analytical error in a system with only a single complex formed [24]. X could also represent the average of a complex population distribution if multiple monorhamnolipid:metal complexes are present, as has been shown for complexes of monorhamnolipids with $\mathrm{Pb}^{2+}$ and $\mathrm{UO}_{2}{ }^{2+}$ [25]. The presence of monorhamnolipid congeners might also explain non-integer molar ratios, as different congeners may have different metal affinities, leading to different metal removal rates and nonuniform molar ratios. Finally, in aqueous media, metal hydroxo complexes or mixed hydroxo-monorhamnolipid complexes may also form resulting in ligand competition that would complicate determination of $X$ values using Eq 1 .

Uranyl $\left(\mathrm{UO}_{2}{ }^{2+}\right)$ the only oxycation in this study was selected because there is significant interest in recovering uranium from seawater in an environmentally compatible manner [26], and uranyl is the most common environmental species of uranium in surface waters [27]. Interestingly, all of the metals tested exhibited plots like those shown in Figure 1B, except for $\mathrm{UO}_{2}{ }^{2+}$. When initially examined, uranyl appeared to exhibit two distinct binding regions (data not shown). A second series of experiments with additional monorhamnolipid concentrations (Fig. 2) confirmed these results. Uranyl clearly exhibits two distinct binding regions. Region 1 has a conditional stability constant value of 3.43, while region 2 has a value of 9.82 . The 
$X$ value determined for region 1 is 0.78 , while region 2 is 2.93 . These two results are included as separate entries in Table 1. The point of this incongruity occurs when the ratio of monorhamnolipids to metal reaches $2: 1$.

There are several possibilities for this unusual behavior. At pH 7, uranyl can form a complex mixture of positively to negatively charged hydroxo species in aqueous media [28]. It is possible the cation binding resin has a greater affinity for a subset of the aqueous uranyl species (e.g., those with higher charge). A second possibility is the formation of mixed ligand species. Positively charged hydroxo species would remain bound to the resin until monorhamnolipid replaced the hydroxo ligands. During ligand exchange, positively-charged mixed-ligand complexes may form and remain bound to the resin. In both possible explanations, release of uranyl complexes would require higher concentrations of monorhamnolipid for effective competition.

A third possible explanation relates to the stoichiometry of the monorhamnolipid: $\mathrm{UO}_{2}{ }^{2+}$ complex. Work by Schalnat [25] reveals at a equimolar concentrations of metal and monorhamnolipid, the $2: 1$ monorhamnolipid: $\mathrm{UO}_{2}{ }^{2+}$ complex is the most abundant species. Thus, under conditions where the ratio of monorhamnolipid: $\mathrm{UO}_{2}{ }^{2+}<2: 1$ (Figure 2, Region 1), the amount of complex formed with $\mathrm{UO}_{2}{ }^{2+}$ is limited, resulting in a smaller conditional stability constant. However, when this ratio exceeds the 2:1 threshold, monorhamnolipid is no longer limiting and the measured stability constant increases (Fig. 2, Region 2).

\subsection{Mixed Metal Studies}


Complexation results using single metals suggest monorhamnolipids have potential for use as metal complexing ligands. However, commercial and industrial applications rarely involve single metal solutions. Since conditional stability constants are reported as $\log$ values, a $\log \beta$ value difference of one means a tenfold difference in preference, favoring the metal with the $\operatorname{larger} \log \beta$. $\log \beta$ values of individual metals should, therefore, predict removal order when monorhamnolipids are applied in a mixed metal solution. This was tested with two mixed metal studies.

The complexation preference of monorhamnolipids for metals with larger log $\beta$ values was examined using a mixture of three metals. $\mathrm{Pb}^{2+}, \mathrm{Cd}^{2+}$ and $\mathrm{Ca}^{2+}$ were selected for the mixed metal study, because these metals represent large (9.13), intermediate (7.17), and small (4.10) $\log \beta$ values. In the first series of experiments, an equimolar amount of each metal was added $(0.167 \mathrm{mM})$ for a total concentration of $0.5 \mathrm{mM}$ metal. As expected, monorhamnolipids complexed $\mathrm{Pb}^{2+}$ much more effectively than $\mathrm{Cd}^{2+}$ or $\mathrm{Ca}^{2+}$ with 81,97 , and $100 \%$ of $\mathrm{Pb}^{2+}$ detected in the aqueous phase at concentrations of 1,2 , and $4 \mathrm{mM}$ of monorhamnolipids, respectively (Fig. 3). In contrast, aqueous phase $\mathrm{Cd}^{2+}$ and $\mathrm{Ca}^{2+}$ were 62 and $15 \%$ of added metal, respectively, at the $4 \mathrm{mM}$ monorhamnolipid concentration. Selectivity coefficients, which describe the partitioning of a ligand between metals, were calculated for the $0.5,1$, and $2 \mathrm{mM}$ monorhamnolipid concentrations (Table 2). From these coefficients, the order of selectivity for monorhamnolipid in this system is $\mathrm{Pb}^{2+}>\mathrm{Cd}^{2+}>\mathrm{Ca}^{2+}$, the same order which is predicted by the metals' conditional stability constants. The $\mathrm{X}$ values calculated for this experiment and 
used to determine the selectivity coefficients were $2.46,1.73$, and 1.59 for $\mathrm{Pb}^{2+}$, $\mathrm{Cd}^{2+}$, and $\mathrm{Ca}^{2+}$, respectively.

Because environmental samples are likely to contain a mixture of target metals and non-target metals in which the latter are present at considerably higher concentrations (e.g., $\mathrm{Ca}^{2+}, \mathrm{K}^{+}$), a second experiment was performed to determine the complexation of metals added at orders of magnitude different concentrations: $0.45 \mathrm{mM} \mathrm{Ca}^{2+}, 0.045 \mathrm{mM} \mathrm{Cd}^{2+}$, and $0.0045 \mathrm{mM} \mathrm{Pb}^{2+}(0.5 \mathrm{mM}$ total metal concentration). Results show 80 and $86 \%$ of $\mathrm{Pb}^{2+}, 14$ and $27 \%$ of $\mathrm{Cd}^{2+}$, and 3 and $5 \%$ of $\mathrm{Ca}^{2+}$ were complexed by 1 and $2 \mathrm{mM}$ monorhamnolipid, respectively (Fig. 4). As expected, in both experiments, removal of metals occurred in the order $\mathrm{Pb}^{2+}>>\mathrm{Cd}^{2+}>\mathrm{Ca}^{2+}$. Table 3 contains a summary of the results for monorhamnolipid complexation of $\mathrm{Pb}^{2+}, \mathrm{Cd}^{2+}$, and $\mathrm{Ca}^{2+}$ in individual and mixed metals studies.

Taken together, the results from the mixed metal studies illustrate the usefulness of conditional stability constants as predictors for metal selectivity and removal order by monorhamnolipids.

\subsection{Determinants of Complexation Strength}

Understanding the determinants of complexation and any associated periodic trends is important for the development and implementation of metal complexing materials. Conditional stability constants for 26 metals are compared herein; the coverage of metals across the periodic table enables examination of the data for trends associated with metal cation physical parameters in relation to metal:monorhamnolipid complexation. Identifying a specific determinant that governs the strength of the metal-monorhamnolipid complex is challenging due to 
numerous factors that play a role in the coordination chemistry. Factors attributable to metal cations include, but are not limited to, cation charge, ionic radius, preferred coordination geometry, electron configuration, crystal field effects, and the Pearson's hardness of the metal. Monorhamnolipid ligand factors include metal binding pocket size, steric interference between monorhamnolipids, molecular conformation, and Pearson's hardness parameter similarity between monorhamnolipids' oxygen (Lewis base) and the reacting metal (Lewis acid)—the strongest and fastest reactions occur between hard-hard and soft-soft acid-base reactions.

Ten physical parameters of the metals were tested for correlation to the conditional stability constant of the metal with monorhamnolipid. Metal:monorhamnolipid conditional stability constants have a significant $(p=<$ 0.0001 ) and strong correlation to enthalpy of hydration (Pearson's $r=0.71$ ) and ion charge (Pearson's $r=0.79$ ). They also have a significant, but less strong correlation to the second ionization potential (Pearsons $r=-0.52$ and $p=0.0080$ ) and charge to ionic radius ratio (Pearson's $r=0.55$ and $p=0.0045$ ) using values from salts with six coordinating anions. These correlations were significant using the Benjamini-Hochberg procedure with a false discovery rate of 0.05 [29]. No significant correlations were found for atomic radius, covalent radius, ionic radius (using values from salts with 6 or 8 coordinating anions), Pauling's electronegativity, or Pearson's hardness parameter (see supplementary Tables S1 and S2 for physical parameter values and correlation values). Though some physical parameters could be correlated to the conditional stability constants, it is 
difficult to predict stability constants using these parameters because they are interrelated. For example, the enthalpy of hydration is defined by both ion size and charge according to the equation $\Delta E=\left(e^{2} / 2 r\right)\left(1-D^{-}\right)$where $\Delta E$ is the energy change, $r$ is the ion radius, $e$ is the charge of the ion, and $D$ is the dielectric constant of the solvent [30]. Correlations of conditional stability constants to enthalpy of hydration, ion charge, second ionization potential, and the charge to radius ratio are in agreement with previously reported determinants for metal and ligand complexation [22, 30].

Localized periodic trends can be found within groups of metals with similar characteristics. For example, the first row transition metals exhibit the IrvingWilliams effect, a general trend in stability constants of $\mathrm{Mn}^{2+}<\mathrm{Fe}^{2+}<\mathrm{Co}^{2+}<\mathrm{Ni}^{2+}<$ $\mathrm{Cu}^{2+}>\mathrm{Zn}^{2+}$ essentially irrespective of the nature of the ligand [22, 31]. Example ligands following this trend include oxalic acid, glycine, salicylaldehyde, ethylenediamine, and ammonia. The data supporting the existence of this trend is observed with monorhamnolipids (supplementary Figure S1). The effect is caused by imperfect shielding of the nucleus as the number of protons increases, with a progressively higher apparent nuclear charge (despite equal formal charges) due to imperfect electron shielding of the nucleus. The stability constant decrease at $\mathrm{Zn}^{2+}$ is the result of complete filling of the d electron set and loss of crystal field stabilization energy [22].

A second example can be found in the REE, or lanthanoids, in the first row of the $f$ block. Due to the electron configurations within the f-block elements, the lanthanoids tend to have very similar coordination chemistry [22]. These metals 
bond with ligands primarily through electrostatic (ionic) interactions with the strongest complexes forming with hard base donors [32] such as the hydroxyl and carboxyl donors of monorhamnolipids. Examination of Table 1 shows these metals behave somewhat predictably: they group together and have high stability constants as predicted for interactions between the lanthanoids and the hard base donor groups of the monorhamnolipids. The REE:monorhamnolipid stability constants do not, however, exhibit the smooth increase in $\log \beta$ characteristic of the lanthanide contraction, unlike previous studies with other ligands such as carbonate, oxalate, 5-sulfosalicylate, a-hydroxyisobutyrate, and floride [33]. Examination of the $95 \%$ confidence intervals in Table 1 suggests the possibility this trend may be obscured by the precision of the method.

When investigating metal-ligand determinants and periodic trends, ligands with unique behaviors or metal selectivity offer novel approaches for metal capture systems. Ligands that follow established trends can be compared to better understand how ligand structure and functional groups affect the size of the conditional stability constant. In the case of monorhamnolipid, the size of monorhamnolipid-metal conditional stability constants correlates to the same determinants and follows metal binding trends reported for other ligands as discussed above. Such comparisons provide important information necessary for future ligand design and development. Furthermore, additional study of biological ligands like monorhamnolipids, may lead to improved design of novel, environmentally friendly, bio-based ligands.

\section{CONCLUSIONS}


Interactions between metals and monorhamnolipids have now been reported for all regions of the periodic table. Results show monorhamnolipids selectively complex economically important metals, such as the critical REE as well as metals of environmental concern, in comparison to common soil and water cations. Results suggest the monorhamnolipid-metal conditional stability constants reported here can be used to predict the removal of metals from mixed metal waste streams. Potential applications for metal recovery using rhamnolipids should be investigated, especially for the rare earth elements.

\section{ACKNOWLEDGEMENTS}

The authors would like to thank Dr. Reyes Sierra for providing the access to and training for the ICP-AES and Ronald Gonzalez for purifying the monorhamnolipids. This work was supported by National Science Foundation (NSF) Graduate Research Fellowship Grant (DGE-1143953) to DEH, NSF Collaborative Research in Chemistry Grant (CHE-0714245), and NSF Networks for Sustainable Molecular Design and Synthesis Grant (CHE-1339597) co-funded with the Environmental Protection Agency for the study of Green Glycolipids.

Two authors of this paper (RMM, JEP) have equity ownership in GlycoSurf, which is developing products related to the research being reported. The terms of this arrangement have been reviewed and approved by the University of Arizona in accordance with its policy on objectivity in research. 


\section{REFERENCES}

[1] U.S. National Research Council, Minerals, critical minerals, and the U.S. economy, National Academies Press, Washington, D.C., 2008.

[2] K. Binnemans, P. Jones, B. Blanpain, T. Gerven, Y. Yang, A. Walton, M. Buchert, Recycling of rare earths: a critical review, J. Clean. Prod. 51 (2013) 1-22.

[3] W.D. Jackson, G. Christiansen, International strategic minerals inventory summary report; rare-earth oxides. Circular 930-N (1993).

[4] Office of Energy Efficiency and Renewable Energy, Financial assistance funding opportunity announcement: Energy innovation hub - critical materials. DE-FOA-0000687 (2012).

[5] EC Ad-hoc Working Group, Critical raw materials for the EU. Critical raw materials for the EU, European Commission (2010).

[6] M. Humphries, Rare earth elements: the global supply chain. Congressional Research Service, Report R41347 (2013).

[7] C.H. Gammons, S.A. Wood, J.P. Jonas, J.P. Madison, Geochemistry of the rare-earth elements and uranium in the acidic Berkeley Pit lake, Butte, Montana, Chem. Geol. 198 (2003) 269-288.

[8] D. Merten, G. Buchel, Determination of rare earth elements in acid mine drainage by inductively coupled plasma mass spectrometry, Microchim. Acta. 148 (2004) 163-170.

[9] C.A. Cravotta, Dissolved metals and associated constituents in abandoned coal-mine discharges, Pennsylvania, USA. Part 1: Constituent quantities and correlations, Appl. Geochem. 23 (2008) 166-202.

[10] F. Zhao, Z. Cong, H. Sun, D. Ren, The geochemistry of rare earth elements (REE) in acid mine drainage from the Sitai coal mine, Shanxi Province, North China, Int. J. Coal Geol. 70 (2007) 184-192.

[11] F. Fu, Q. Wang, Removal of heavy metal ions from wastewaters: a review, J. Environ. Manage. 92 (2011) 407-418.

[12] P.L. Verplanck, E.T. Furlong, J.L. Gray, P.J. Phillips, R.E. Wolf, K. Esposito, Evaluating the behavior of gadolinium and other rare earth elements through 
large metropolitan sewage treatment plants, Environ. Sci. Technol. 44 (2010) 3876-3882.

[13] P. Kiddee, R. Naidu, M.H. Wong, L. Hearn, J.F. Muller, Field investigation of the quality of fresh and aged leachates from selected landfills receiving ewaste in an arid climate, Waste Manage. 34 (2014) 2292-2304.

[14] A.M. Abdel-Mawgoud, F. Lepine, E. Deziel, Rhamnolipids: diversity of structures, microbial origins and roles, Appl. Microbiol. Biotechnol. 86 (2010) 1323-1336.

[15] H. Tan, J.T. Champion, J.F. Artiola, M.L. Brusseau, R.M. Miller, Complexation of cadmium by a rhamnolipid biosurfactant, Environ. Sci. Technol. 28 (1994) 2402-2406.

[16] D.C. Herman, J.F. Artiola, R.M. Miller, Removal of cadmium, lead, and zinc from soil by a rhamnolipid biosurfactant, Environ. Sci. Technol. 29 (1995) 2280-2285.

[17] F.J. Ochoa-Loza, J.F. Artiola, R.M. Maier, Stability constants for the complexation of various metals with a rhamnolipid biosurfactant, J. Environ. Qual. 30 (2001) 479-485.

[18] J.P. Giesy, J.J. Alberts, Conditional stability-constants and binding-capacities for copper(ii) by ultrafilterable material isolated from six surface waters of wyoming, USA, Hydrobiologia. 188 (1989) 659-680.

[19] A. Lebron-Paler, J.E. Pemberton, B.A. Becker, W.H. Otto, C.K. Larive, R.M. Maier, Determination of the acid dissociation constant of the biosurfactant monorhamnolipid in aqueous solution by potentiometric and spectroscopic methods, Anal. Chem. 78 (2006) 7649-7658.

[20] A. Lebron-Paler, Solution and interfacial characterization of rhamnolipid biosurfactant from P. aeruginosa ATCC 9027, ProQuest, 2008.

[21] L. Zhang, J.E. Pemberton, R.M. Maier, Effect of fatty acid substrate chain length on Pseudomonas aeruginosa ATCC 9027 monorhamnolipid yield and congener distribution, Process Biochem. 49 (2014) 989-995.

[22] G.A. Lawrance, Stability, in: Introduction to coordination chemistry, Wiley, Chichester, U.K, 2010, pp. 125-171. 
[23] L. Hendrickson, R. Corey, Effect of equilibrium metal concentrations on apparent selectivity coefficients of soil complexes, Soil Sci. 131 (1981) 163171.

[24] M. Schnitzer, E.H. Hansen, Organo-metallic interactions in soils: 8. an evaluation of methods for determination of stability constants of metal-fulvic acid complexes, Soil Sci. 109 (1970) 333-340.

[25] T.A. Schalnat, Metal complexation and interfacial behavior of the microbiallyproduced surfactant monorhamnolipid by Pseudomonas aeruginosa ATCC 9027, ProQuest, 2012.

[26] S.D. Alexandratos, S. Kung, Preface to the special issue: uranium in seawater, Ind. Eng. Chem. Res. 55 (2016) 4101-4102.

[27] S.J. Markich, Uranium speciation and bioavailability in aquatic systems: an overview, Sci. World J. 2 (2002) 707-729.

[28] A. Krestou, D. Panias, Uranium (VI) speciation diagrams in the $\mathrm{UO}_{2}^{2+} / \mathrm{CO}_{3}{ }^{2-} /$ $\mathrm{H}_{2} \mathrm{O}$ system at $25^{\circ} \mathrm{C}$, Eur. J. Min. Proc. Environ. Prot. 4 (2004) 113.

[29] Y. Benjamini, Y. Hochberg, Controlling the false discovery rate: a practical and powerful approach to multiple testing, J. Roy. Stat. Soc. B Met. 57 (1995) 289-300.

[30] A.E. Martell, M. Calvin, Effect of metal ion, in: W.M. Latimer (Ed.), Chemistry of the metal chelate compounds, Prentice-Hall, Inc, Englewood Cliffs, NJ, 1952, pp. 181-206.

[31] H. Irving, R.J.P. Williams, 637. The stability of transition-metal complexes, J. Chem. Soc. (1953) 3192-3210.

[32] D.T. Richens, Introduction, in: The chemistry of aqua ions: synthesis, structure, and reactivity: a tour through the periodic table of the elements, J. Wiley, Chichester; New York, 1997, pp. 1-120.

[33] K. Cantrell, R. Byrne, Rare-earth element complexation by carbonate and oxalate ions, Geochim. Cosmochim. Acta. 51 (1987) 597-605. 


\section{FIGURE CAPTIONS}

Figure 1 (A) Effect of monorhamnolipid concentration on the complexation of $\mathrm{Pb}^{2+}$ and $\mathrm{Sr}^{2+}$. (B) Determination of the conditional stability constant and stoichiometry of monorhamnolipid:metal complexes by ion-exchange equilibrium method for $\mathrm{Pb}^{2+}$ and $\mathrm{Sr}^{2+}$. Each metal was tested independently. Insert: Structure of monorhamnolipids utilized in this study. The varying chain lengths of the monorhamnolipid congeners are represented by ' $m$ ' and ' $n$ ' which vary from 4 to 12.

Figure 2 Determination of conditional stability constant and stoichiometry of monorhamnolipid: $\mathrm{UO}_{2}{ }^{2+}$ complexes by ion-exchange equilibrium method. The circled symbol indicates the monorhamnolipid concentration where the monorhamnolipid:metal ratio is 2:1. Region 1 and 2 indicate the two distinct binding regions of monorhamnolipid with uranyl.

Figure 3 Effect of monorhamnolipid concentration on complexation of $\mathrm{Pb}^{2+}, \mathrm{Cd}^{2+}$, and $\mathrm{Ca}^{2+}$ in an equimolar metal mixture (each metal was added at a concentration of $0.167 \mathrm{mM})$.

Figure 4 Effect of monorhamnolipid concentration on complexation of $\mathrm{Pb}^{2+}, \mathrm{Cd}^{2+}$, and $\mathrm{Ca}^{2+}$ in a $100: 10: 1\left(\mathrm{Ca}^{2+}: \mathrm{Cd}^{2+}: \mathrm{Pb}^{2+}\right)$ metal mixture. 
Table 1. Conditional stability constants, molar ratios, and statistical analysis for metal complexes with monorhamnolipids

\begin{tabular}{|c|c|c|c|c|c|c|c|c|c|c|c|}
\hline \multirow[b]{2}{*}{ Metal Ion } & \multirow[b]{2}{*}{$\log \beta$} & \multirow{2}{*}{$\begin{array}{c}\text { Std. Error } \\
\log \beta \\
\end{array}$} & \multicolumn{2}{|c|}{$\begin{array}{l}\text { 95\% Conf. Limits } \\
\log \beta\end{array}$} & \multirow[b]{2}{*}{$x$} & \multirow{2}{*}{$\begin{array}{c}\text { Std. error } \\
x \\
\end{array}$} & \multicolumn{2}{|c|}{$\begin{array}{c}\text { 95\% Conf. Limits } \\
\mathrm{X} \\
\end{array}$} & \multirow[b]{2}{*}{$\mathbf{R}^{2}$} & \multicolumn{2}{|c|}{$\begin{array}{l}\text { Coefficient of } \\
\text { Variation (\%) }\end{array}$} \\
\hline & & & Lower & Upper & & & Lower & Upper & & $\log \beta$ & $x$ \\
\hline${ }^{\ddagger *} \mathrm{Al}^{3+}$ & 10.30 & 0.732 & 8.26 & 12.33 & 2.48 & 0.242 & 1.80 & 3.15 & 0.963 & 7.1 & 9.8 \\
\hline${ }^{+} \mathrm{UO}_{2}{ }^{2+}$ & 9.82 & 1.328 & 6.99 & 11.74 & 2.93 & 0.467 & 1.90 & 3.58 & 0.975 & 13.5 & 16.0 \\
\hline $\mathrm{Eu}^{3+}$ & 9.77 & 0.202 & 9.34 & 10.62 & 2.17 & 0.065 & 2.00 & 2.45 & 0.997 & 2.1 & 3.0 \\
\hline $\mathrm{Nd}^{3+}$ & 9.69 & 0.459 & 8.28 & 11.32 & 2.19 & 0.147 & 1.65 & 2.71 & 0.987 & 4.7 & 6.7 \\
\hline $\mathrm{Tb}^{3+}$ & 9.65 & 0.382 & 8.27 & 10.88 & 2.01 & 0.122 & 1.49 & 2.39 & 0.989 & 4.0 & 6.1 \\
\hline $\mathrm{Dy}^{3+}$ & 9.57 & 0.592 & 7.27 & 10.93 & 2.14 & 0.189 & 1.29 & 2.51 & 0.977 & 6.2 & 8.8 \\
\hline $\mathrm{La}^{3+}$ & 9.29 & 0.432 & 8.14 & 10.86 & 2.07 & 0.138 & 1.77 & 2.61 & 0.987 & 4.6 & 6.7 \\
\hline$* \mathrm{Cu}^{2+}$ & 9.27 & 0.659 & 7.43 & 11.10 & 2.31 & 0.218 & 1.70 & 2.91 & 0.966 & 7.1 & 9.4 \\
\hline $\mathrm{Al}^{3+}$ & 9.22 & 0.937 & 5.08 & 11.13 & 2.35 & 0.299 & 0.95 & 2.86 & 0.954 & 10.2 & 12.7 \\
\hline $\mathrm{Pb}^{2+}$ & 9.13 & 0.223 & 8.71 & 10.12 & 2.23 & 0.071 & 2.12 & 2.56 & 0.997 & 2.4 & 3.2 \\
\hline $\mathrm{Y}^{3+}$ & 9.11 & 0.201 & 8.59 & 9.96 & 2.04 & 0.064 & 1.88 & 2.32 & 0.997 & 2.2 & 3.2 \\
\hline $\mathrm{Pr}^{3+}$ & 9.04 & 0.223 & 8.53 & 9.83 & 1.98 & 0.071 & 1.84 & 2.25 & 0.996 & 2.5 & 3.6 \\
\hline$\neq * \mathrm{~Pb}^{2+}$ & 8.58 & 1.132 & 5.43 & 11.73 & 2.37 & 0.374 & 1.32 & 3.41 & 0.909 & 13.2 & 15.8 \\
\hline $\mathrm{Lu}^{3+}$ & 8.20 & 0.247 & 7.69 & 9.16 & 1.72 & 0.079 & 1.51 & 2.02 & 0.994 & 3.0 & 4.6 \\
\hline $\mathrm{Cd}^{2+}$ & 7.17 & 0.735 & 5.28 & 9.41 & 2.04 & 0.235 & 1.50 & 2.86 & 0.962 & 10.3 & 11.5 \\
\hline${ }^{\ddagger} * \mathrm{Cd}^{2+}$ & 6.89 & 0.246 & 6.21 & 7.57 & 1.91 & 0.081 & 1.68 & 2.13 & 0.993 & 3.6 & 4.2 \\
\hline $\ln ^{3+}$ & 6.70 & 1.129 & 3.65 & 10.18 & 1.75 & 0.361 & 0.92 & 3.03 & 0.886 & 16.8 & 20.7 \\
\hline$* \mathrm{Zn}^{2+}$ & 5.62 & 0.214 & 5.03 & 6.22 & 1.58 & 0.071 & 1.39 & 1.78 & 0.992 & 3.8 & 4.5 \\
\hline$* \mathrm{Fe}^{3+}$ & 5.16 & 0.710 & 3.19 & 7.13 & 1.22 & 0.235 & 0.55 & 1.85 & 0.867 & 13.8 & 19.3 \\
\hline
\end{tabular}




\begin{tabular}{cccccccccccc}
$* \mathrm{Hg}^{2+}$ & 4.49 & 0.135 & 4.11 & 4.87 & 1.21 & 0.045 & 1.09 & 1.34 & 0.995 & 3.0 & 3.7 \\
${ }^{*} \mathrm{Ca}^{2+}$ & 4.10 & 0.635 & 2.33 & 5.86 & 1.32 & 0.210 & 0.74 & 1.90 & 0.908 & 15.5 & 15.9 \\
$\mathrm{Sr}^{2+}$ & 3.95 & 0.095 & 3.52 & 4.13 & 1.39 & 0.030 & 1.24 & 1.44 & 0.999 & 2.4 & 2.2 \\
${ }^{*} \mathrm{Co}^{2+}$ & 3.58 & 0.150 & 3.17 & 4.00 & 1.03 & 0.049 & 0.89 & 1.17 & 0.991 & 4.2 & 4.8 \\
${ }^{*} \mathrm{Ni}^{2+}$ & 3.53 & 0.176 & 3.04 & 4.02 & 0.93 & 0.058 & 0.77 & 1.09 & 0.984 & 5.0 & 6.2 \\
${ }^{+} \mathrm{UO}_{2}{ }^{2+}$ & 3.43 & 0.419 & 2.25 & 5.09 & 0.78 & 0.128 & 0.44 & 1.30 & 0.949 & 12.2 & 16.5 \\
$\mathrm{Ba}^{2+}$ & 3.22 & 0.438 & 1.97 & 4.36 & 1.10 & 0.140 & 0.66 & 1.40 & 0.954 & 13.6 & 12.7 \\
${ }^{*} \mathrm{Mn}^{2+}$ & 2.85 & 0.452 & 1.59 & 4.10 & 0.90 & 0.150 & 0.49 & 1.32 & 0.901 & 15.9 & 16.7 \\
${ }^{*} \mathrm{Mg}^{2+}$ & 2.66 & 0.315 & 1.80 & 3.55 & 0.84 & 0.104 & 0.55 & 1.13 & 0.942 & 11.8 & 12.4 \\
$\mathrm{Rb}^{+}$ & 1.57 & 0.291 & 1.13 & 2.30 & 0.85 & 0.096 & 0.72 & 1.09 & 0.963 & 18.6 & 11.3 \\
${ }^{*} \mathrm{~K}^{+}$ & 0.96 & 0.115 & 0.64 & 1.28 & 0.57 & 0.038 & 0.47 & 0.68 & 0.983 & 12.0 & 6.7 \\
\hline
\end{tabular}

*Values from Ochoa-Loza et al. [17]

$+\mathrm{UO}_{2}{ }^{2+}$ had two distinct binding regions, and each region is included separately.

$\ddagger$ Values from Ochoa-Loza et al. [17] omitted from subsequent discussion (section 3.1) and statistical analyses (section 3.3) because values for these metals were calculated in this study. 
Table 2. Selectivity coefficients for the equimolar mixed metal system

\begin{tabular}{cccc}
\hline \hline $\begin{array}{c}\text { Monorhamnolipid } \\
(\mathbf{m M})\end{array}$ & $\begin{array}{c}\log \\
\left(\mathrm{K}_{\mathrm{Ca}}{ }^{\mathrm{Pb}}\right)\end{array}$ & $\begin{array}{c}\text { Log } \\
\left(\mathrm{K}_{\mathrm{Cd}}{ }^{\mathrm{Pb}}\right)\end{array}$ & $\begin{array}{c}\log \\
\left(\mathrm{K}_{\mathrm{Ca}}{ }^{{ }^{2 d}}\right)\end{array}$ \\
\hline 0.5 & 5.7 & 4.4 & 1.3 \\
1 & 5.2 & 4.3 & 1.0 \\
2 & 5.2 & 4.3 & 0.9 \\
\hline
\end{tabular}


Table 3. Monorhamnolipid-metal complexation in single and mixed metal systems.

\begin{tabular}{|c|c|c|c|c|}
\hline & & \multicolumn{3}{|c|}{ Monorhamnolipid Concentration } \\
\hline & & $1 \mathrm{mM}$ & $2 \mathrm{mM}$ & $4 \mathrm{mM}$ \\
\hline & & Complexed & Complexed & Complexed \\
\hline & & Metal $(\mu \mathrm{M})$ & Metal ( $\mu \mathrm{M})$ & Metal $(\mu \mathrm{M})$ \\
\hline \multirow{3}{*}{ 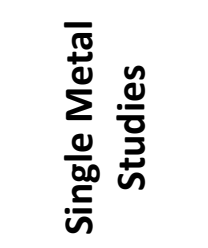 } & $\mathrm{Pb}^{2+}(500 \mu \mathrm{M})$ & 342 & 466 & 524 \\
\hline & $\mathrm{Cd}^{2+}(500 \mu \mathrm{M})$ & 97 & 190 & 288 \\
\hline & $\mathrm{Ca}^{2+}(500 \mu \mathrm{M})$ & $12^{\mathrm{a}}$ & $22^{\mathrm{a}}$ & $44^{a}$ \\
\hline \multirow{3}{*}{ 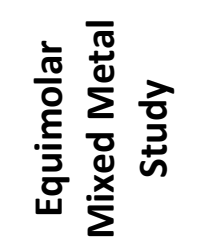 } & $\mathrm{Pb}^{2+}(167 \mu \mathrm{M})$ & 144 & 169 & 175 \\
\hline & $\mathrm{Cd}^{2+}(167 \mu \mathrm{M})$ & 19 & 62 & 104 \\
\hline & $\mathrm{Ca}^{2+}(167 \mu \mathrm{M})$ & 2.7 & 10 & 25 \\
\hline \multirow{3}{*}{ 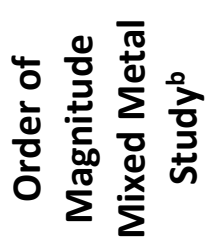 } & $\mathrm{Pb}^{2+}(4.5 \mu \mathrm{M})$ & 3.9 & 4.2 & \\
\hline & $\mathrm{Cd}^{2+}(45 \mu \mathrm{M})$ & 6.4 & 13 & \\
\hline & $\mathrm{Ca}^{2+}(450 \mu \mathrm{M})$ & 14 & 24 & \\
\hline
\end{tabular}

aValues calculated based on data from Ochoa Loza et al. [17]

b $1 \mathrm{~Pb} 2+$ : $10 \mathrm{Cd} 2+$ : $100 \mathrm{Ca}+$ 
Figure 1
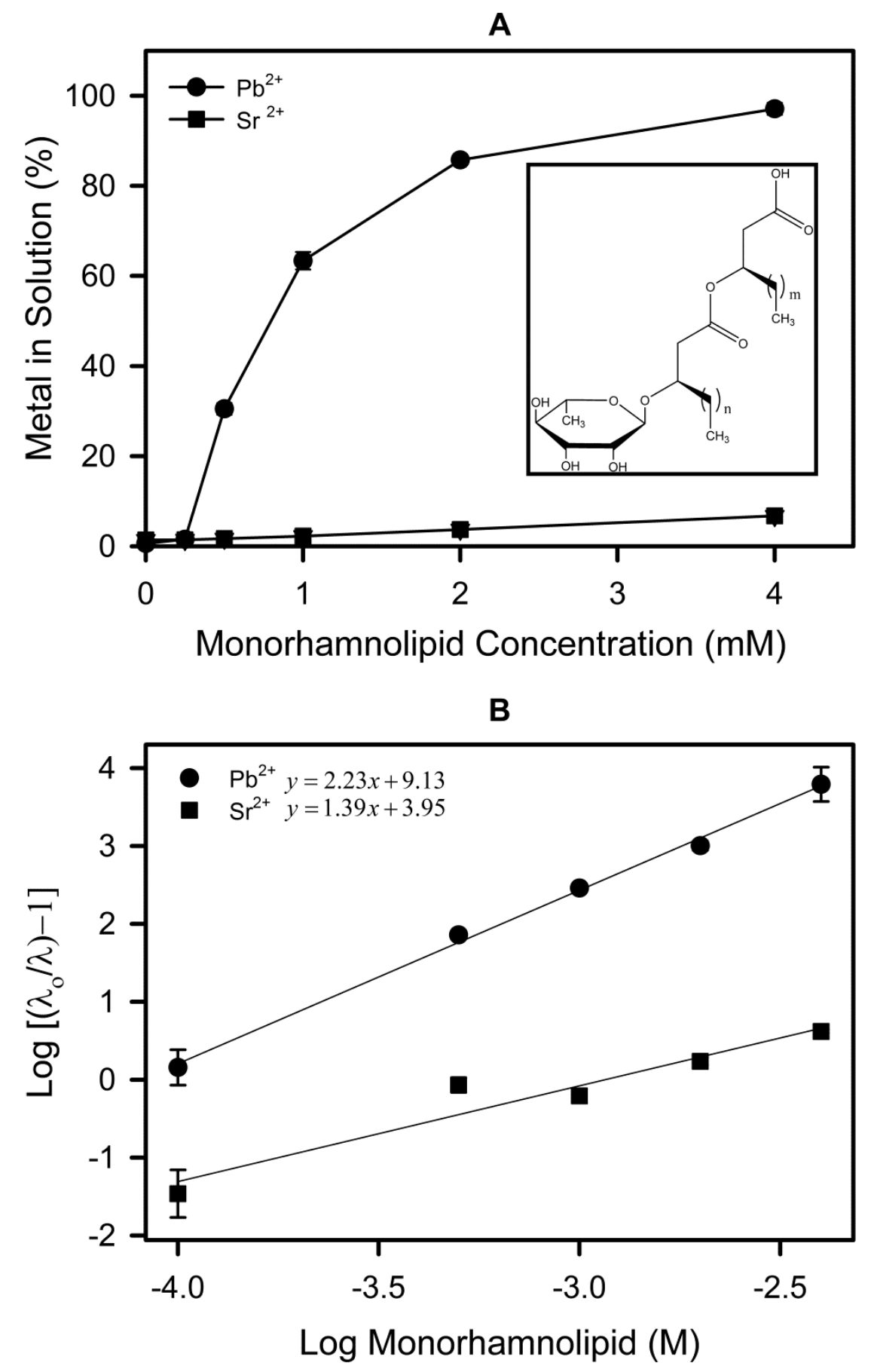

Page 29 of 37 
Figure 2

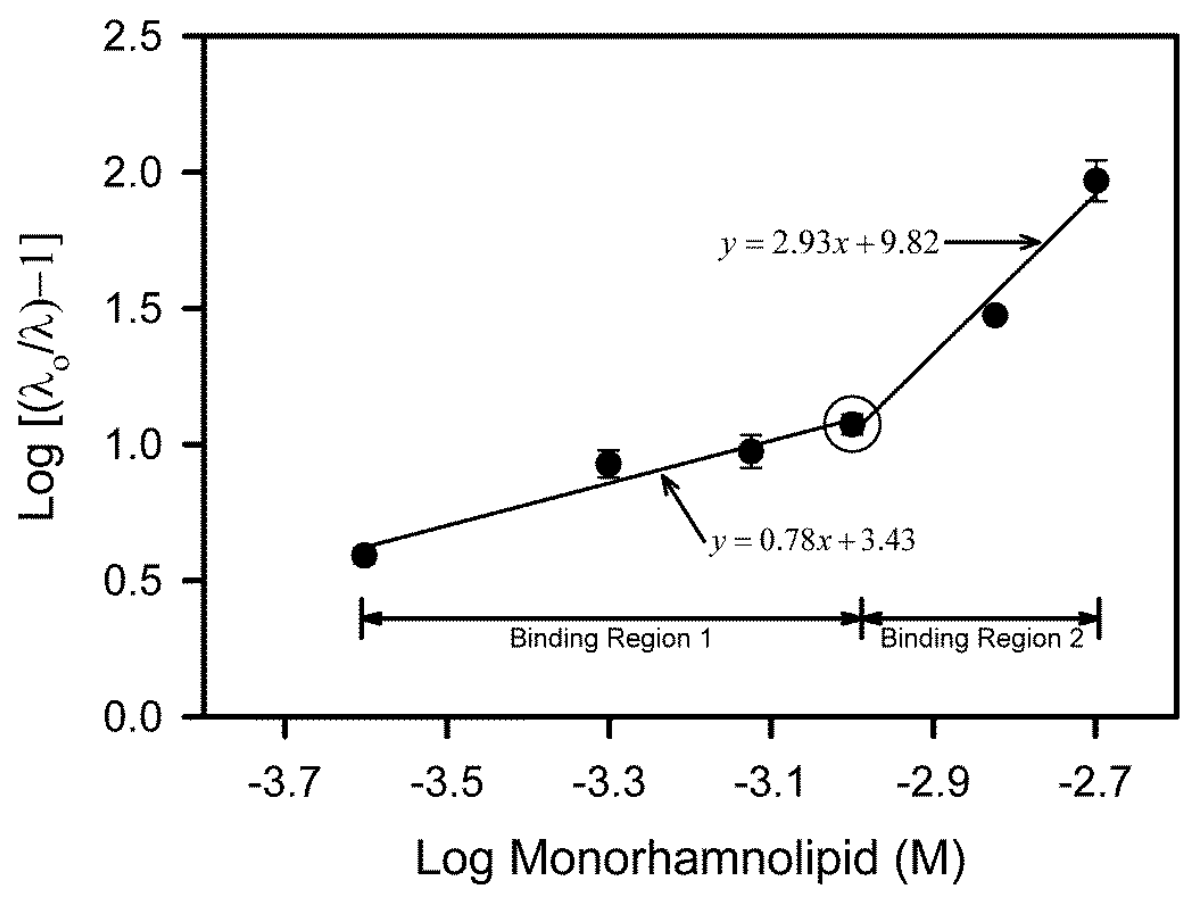

Page 30 of 37 
Figure 3

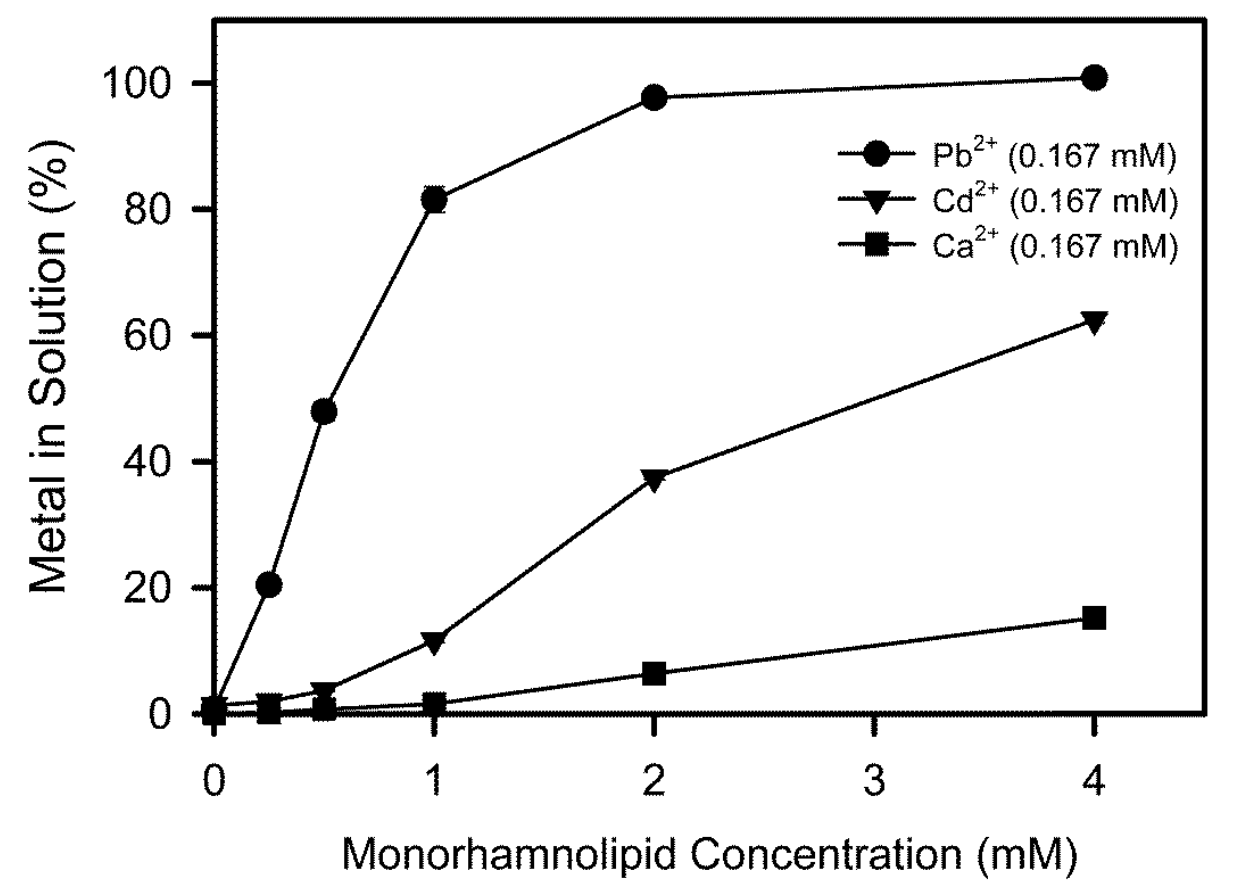

Page 31 of 37 
Figure 4

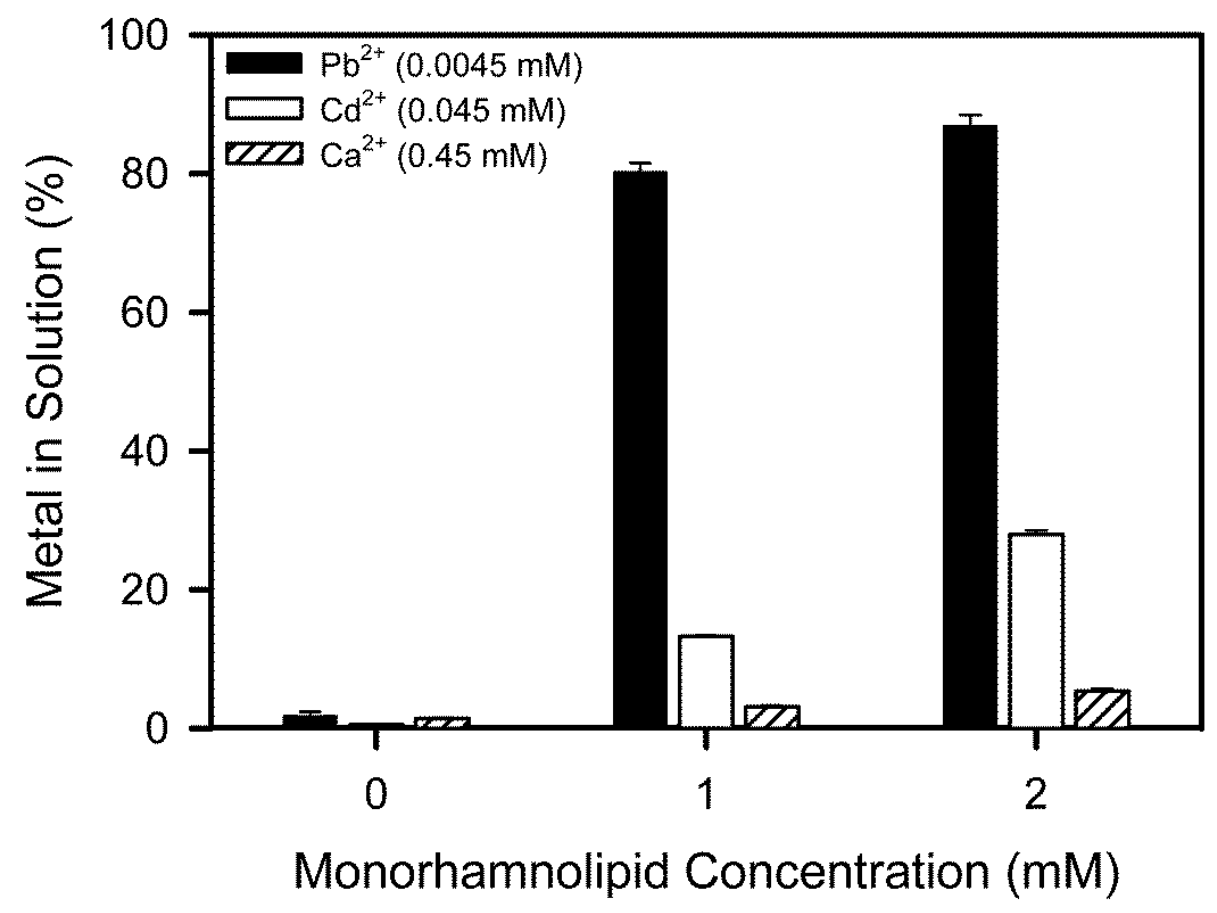

Page 32 of 37 


\section{RHAMNOLIPID BIOSURFACTANT COMPLEXATION OF RARE EARTH ELEMENTS: Supplementary Materials}

David E. Hogan ${ }^{a}$, Joan E. Curry ${ }^{a}$, Jeanne E. Pemberton ${ }^{b}$, and Raina M. Maiera*

${ }^{a}$ Department of Soil, Water and Environmental Science, University of Arizona, P.O. Box 210038, Tucson, AZ 85721

${ }^{\mathrm{b}}$ Department of Chemistry and Biochemistry, University of Arizona, P.O. Box 210041, Tucson, AZ 85721

*rmaier@cals.arizona.edu 
Table S1. Values used to determine correlations between metal-monorhamnolipid conditional stability constants and physical parameters.

\begin{tabular}{|c|c|c|c|c|c|c|c|c|c|c|}
\hline \multirow[b]{2}{*}{$\begin{array}{l}\text { Metal } \\
\text { Ion }\end{array}$} & \multirow[b]{2}{*}{$\underset{\beta}{\log }$} & \multirow[b]{2}{*}{$\begin{array}{c}\text { Charge } \\
(+)\end{array}$} & \multirow[b]{2}{*}{$\begin{array}{c}\text { Atomic } \\
\text { Radius }^{\text {a }} \\
(\AA)\end{array}$} & \multirow[b]{2}{*}{$\begin{array}{c}\text { Covalent } \\
\text { Radius }^{\text {a }} \\
(\AA ̊)\end{array}$} & \multicolumn{2}{|c|}{ Ionic Radius ${ }^{\text {b }}$} & \multirow[b]{2}{*}{$\begin{array}{l}\text { Pauling's } \\
\text { Electronegativity }^{\mathrm{a}}\end{array}$} & \multirow[b]{2}{*}{$\begin{array}{l}\text { Hydration } \\
\text { Enthalpy } \\
\left(-\mathrm{kJ} \mathrm{mol}^{-1}\right)\end{array}$} & \multirow{2}{*}{$\begin{array}{c}\text { Pearson's } \\
\text { Hardness } \\
\text { Parameter d } \\
\text { (eV) }\end{array}$} & \multirow{2}{*}{$\begin{array}{c}\text { Ionization } \\
\text { Potential } \\
\text { (II) } \\
\text { (eV) }\end{array}$} \\
\hline & & & & & $\begin{array}{c}\text { 6- } \\
\text { Coordinated } \\
(\AA)\end{array}$ & $\begin{array}{c}\text { 8- } \\
\text { Coordinated } \\
(\AA)\end{array}$ & & & & \\
\hline $\mathrm{Eu}^{3+}$ & 9.77 & 3 & 2.56 & 1.85 & 0.947 & 1.066 & 1.20 & 3600 & & 11.25 \\
\hline $\mathrm{Nd}^{3+}$ & 9.69 & 3 & 2.64 & 1.64 & 0.983 & 1.109 & 1.14 & 3420 & & 10.72 \\
\hline $\mathrm{Tb}^{3+}$ & 9.65 & 3 & 2.51 & 1.59 & 0.923 & 1.04 & 1.10 & 3540 & & 11.52 \\
\hline $\mathrm{Dy}^{3+}$ & 9.57 & 3 & 2.49 & 1.59 & 0.912 & 1.027 & 1.22 & 3570 & & 11.67 \\
\hline $\mathrm{La}^{3+}$ & 9.29 & 3 & 2.74 & 1.25 & 1.032 & 1.16 & 1.10 & 3296 & 15.4 & 11.059 \\
\hline $\mathrm{Al}^{3+}$ & 9.22 & 3 & 1.82 & 1.18 & 0.535 & & 1.61 & 4665 & 45.8 & 18.829 \\
\hline $\mathrm{Y}^{3+}$ & 9.11 & 3 & 2.27 & 1.62 & 0.9 & 1.019 & 1.22 & 3583 & & 12.224 \\
\hline $\mathrm{Pr}^{3+}$ & 9.04 & 3 & 2.67 & 1.65 & 0.99 & 1.126 & 1.13 & 3405 & & 10.55 \\
\hline $\mathrm{Lu}^{3+}$ & 8.20 & 3 & 2.25 & 1.56 & 0.861 & 0.977 & 1.27 & 3530 & & 13.9 \\
\hline $\ln ^{3+}$ & 6.70 & 3 & 2.00 & 1.44 & 0.8 & 0.92 & 1.78 & 4112 & & 18.870 \\
\hline $\mathrm{Fe}^{3+}$ & 5.16 & 3 & 1.72 & 1.17 & 0.645 & 0.78 & 1.83 & 4430 & 13.1 & 16.188 \\
\hline $\mathrm{Cu}^{2+}$ & 9.27 & 2 & 1.57 & 1.17 & 0.73 & & 1.90 & 2100 & 8.3 & 20.292 \\
\hline $\mathrm{Pb}^{2+}$ & 9.13 & 2 & 1.81 & 1.47 & 1.19 & 1.29 & 2.33 & 1481 & 8.5 & 15.032 \\
\hline $\mathrm{Cd}^{2+}$ & 7.17 & 2 & 1.71 & 1.41 & 0.95 & 1.1 & 1.69 & 1807 & 10.3 & 16.908 \\
\hline $\mathrm{Zn}^{2+}$ & 5.62 & 2 & 1.53 & 1.25 & 0.74 & 0.9 & 1.65 & 2046 & 10.8 & 17.964 \\
\hline $\mathrm{Hg}^{2+}$ & 4.49 & 2 & 1.76 & 1.49 & 0.72 & 0.89 & 2.00 & 1824 & 7.7 & 18.757 \\
\hline $\mathrm{Ca}^{2+}$ & 4.10 & 2 & 2.23 & 1.74 & 1 & 1.12 & 1.00 & 1577 & & 11.872 \\
\hline $\mathrm{Sr}^{2+}$ & 3.95 & 2 & 2.45 & 1.91 & 1.18 & 1.26 & 0.95 & 1443 & & 11.030 \\
\hline $\mathrm{Co}^{2+}$ & 3.58 & 2 & 1.67 & 1.16 & 0.745 & 0.9 & 1.88 & 1996 & & 17.084 \\
\hline $\mathrm{Ni}^{2+}$ & 3.53 & 2 & 1.62 & 1.15 & 0.69 & & 1.91 & 2105 & 8.5 & 18.169 \\
\hline $\mathrm{Ba}^{2+}$ & 3.22 & 2 & 2.78 & 1.98 & 1.35 & 1.42 & 0.89 & 1305 & 12.8 & 10.004 \\
\hline $\mathrm{Mn}^{2+}$ & 2.85 & 2 & 1.79 & 1.17 & 0.83 & 0.96 & 1.55 & 1841 & & 15.640 \\
\hline $\mathrm{Mg}^{2+}$ & 2.66 & 2 & 1.72 & 1.36 & 0.72 & 0.89 & 1.31 & 1921 & 32.5 & 15.035 \\
\hline
\end{tabular}




\begin{tabular}{ccccccccccc}
$\mathrm{Rb}^{+}$ & 1.57 & 1 & 2.98 & 2.16 & 1.52 & 1.61 & 0.82 & 293 & 11.7 & 27.290 \\
$\mathrm{~K}^{+}$ & 0.96 & 1 & 2.77 & 2.03 & 1.38 & 1.51 & 0.82 & 322 & 31.63 \\
\hline
\end{tabular}

a Periodic Table of the Elements. VWR/Sargent-Welch, 1998

${ }^{\mathrm{b}}$ Shannon, R.D., 1976. Revised effective ionic radii and systematic studies of interatomic distances in halides and chalcogenides. Acta Cryst. $32,751-767$.

' Smith, D.W, 1977. Ionic hydration enthalpies. J. Chem. Educ. 54, 540-542.

d Parr, R.G., Pearson, R.G., 1983. Absolute hardness: companion parameter to absolute electronegativity. J. Am. Chem. Soc. 105, 75127516.

e Haynes, W.M., 2016. CRC Handbook of Chemistry and Physics, $97^{\text {th }}$ ed. CRC Press, New York. 
Table S2. Pearson's correlation coefficients of metal:monorhamnolipid conditional stability constants and the physical parameters of metals which complex with monorhamnolipid

\begin{tabular}{cccc} 
Physical Parameter & $\begin{array}{c}\text { Pearson's Correlation } \\
\text { Coefficient }(r)\end{array}$ & $\begin{array}{c}\text { Significance Probability } \\
\text { ( } \mathbf{p} \text {-value) }\end{array}$ & $\begin{array}{c}\text { Benjamini-Hochberg } \\
\text { adjusted } \mathbf{p} \text {-value (q- } \\
\text { value) }\end{array}$ \\
\hline Atomic Radius & 0.0648 & 0.7582 & 0.7582 \\
Covalent Radius & -0.2080 & 0.3183 & 0.4547 \\
$\begin{array}{c}\text { Ionic Radius } \\
\text { (Coordination Number 6) } \\
\quad \text { lonic Radius }\end{array}$ & -0.2730 & 0.1868 & 0.3736 \\
$\begin{array}{c}\text { (Coordination Number 8) } \\
\text { Pauling's } \\
\text { Electronegativity }\end{array}$ & -0.2696 & 0.2251 & 0.3752 \\
$\begin{array}{c}\text { Enthalpy of Hydration } \\
\text { Pearson's Hardness } \\
\text { Parameter }\end{array}$ & 0.1410 & 0.5013 & 0.6266 \\
$\begin{array}{c}\text { Charge/lonic Radius } \\
\text { (Coordination Number 6) }\end{array}$ & 0.7145 & $<0.0001$ & 0.0005 \\
$\quad$ lon Charge & 0.1252 & 0.6983 & 0.7582 \\
$\begin{array}{c}\text { Second lonization } \\
\text { Potential }\end{array}$ & 0.7884 & 0.0045 & 0.015 \\
\hline
\end{tabular}




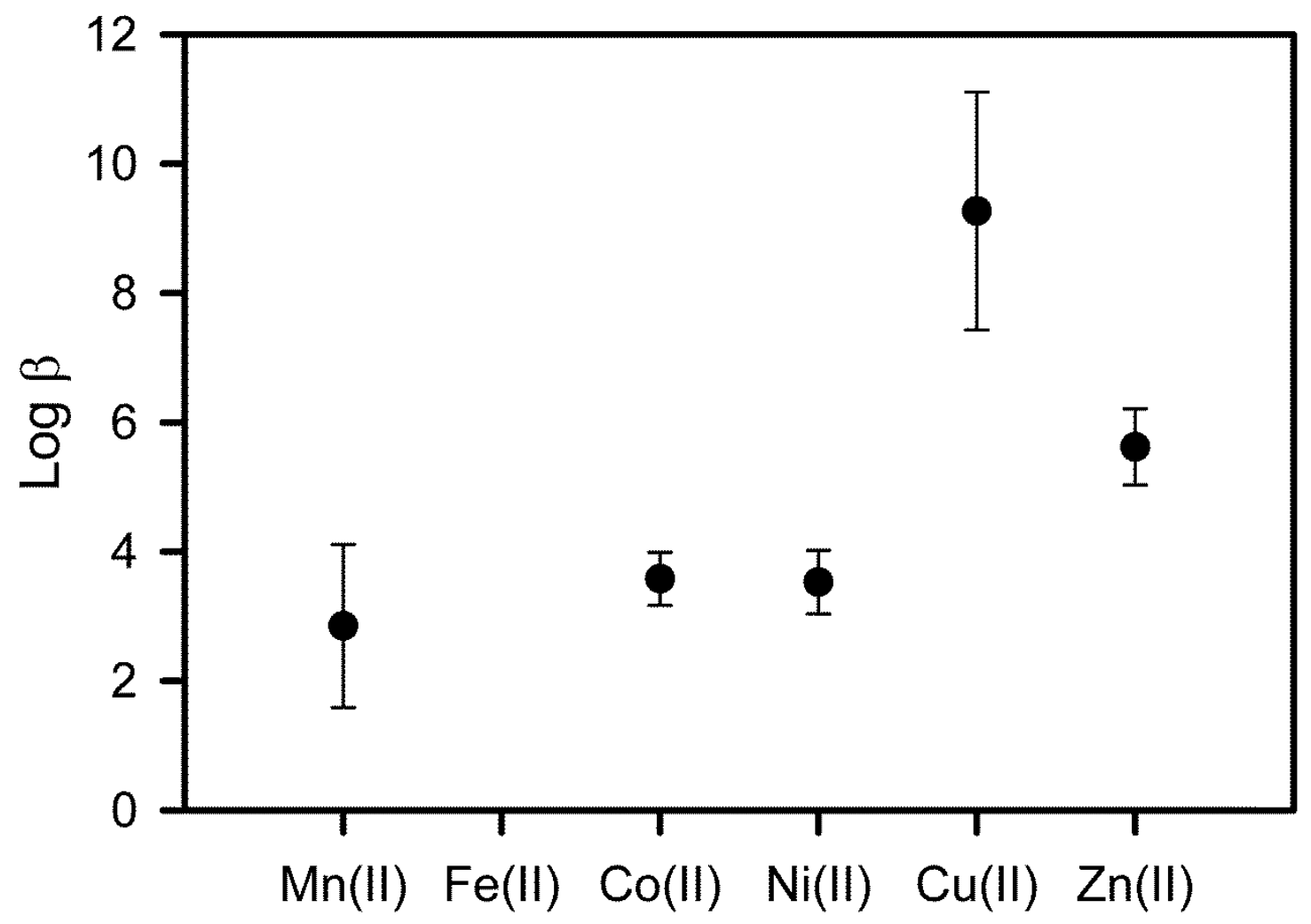

Figure S1 $\log \beta$ values for the first row transition elements from $\mathrm{Mn}(\mathrm{II})$ to $\mathrm{Zn}(\mathrm{II})$ demonstrating the Irving-Williams effect. Error bars represent 95\% confidence intervals. 